\title{
DNA damage sensor protein hRad9, a novel molecular target for lung cancer treatment
}

\author{
TAKESHI YUKI ${ }^{1}$, YOSHIMASA MANIWA ${ }^{1}$, TAKEFUMI DOI $^{3}$, KENJI OKADA $^{2}$, \\ WATARU NISHIO $^{1}$, YOSHITAKE HAYASHI ${ }^{3}$ and YUTAKA OKITA $^{1}$ \\ Divisions of ${ }^{1}$ Thoracic Surgery, ${ }^{2}$ Cardiovascular Surgery, ${ }^{3}$ Molecular Medicine and \\ Medical Genetics, International Center for Medical Research and Treatment (ICMRT), \\ Kobe University Graduate School of Medicine, Kobe 650-0017, Japan
}

Received October 30, 2007; Accepted February 19, 2008

DOI: 10.3892/or_00000108

\begin{abstract}
DNA damage sensor proteins are recognized as upstream components of the DNA damage checkpoint signaling pathway and are required for cell cycle control and the induction of apoptosis. hRad9 plays an important role as an upstream regulator of checkpoint signaling. In our previous studies, we confirmed the significant accumulation of hRad9 in the nuclei of tumor cells in surgically-resected non-small cell lung cancer (NSCLC) specimens. We also found that the capacity to produce a functional hRad9 protein was intact in lung cancer cells, a finding which suggests that hRad9 would be a vital component in the pathways that lead to the survival and progression of NSCLC. Small interfering RNA targeting hRad9 was transfected into human lung adenocarcinoma A549 and PC3 cells. After the hRad9 knockdown, the cytotoxicity of the transfected cells was measured by a neutral red uptake test, and the G2-M arrest of irradiated cells was examined by flow cytometry. Significant cytotoxicity was observed in the cancer cells in which hRad9 expression was down-regulated. We also detected the inhibition of Chk1 phosphorylation by Western blot analysis. This suggested that hRad9 silencing leads to the impairment of the DNA damage checkpoint signaling pathway in tumor cells. Flow cytometry indicated a reduced population of cells in the G2-M phase, an observation consistent with the findings of several studies that indicated that hRad9 is necessary for G2-M arrest. In conclusion, the current study demonstrated that RNA interference targeting hRad9 in cancer cells leads to the impairment of the DNA damage checkpoint signaling
\end{abstract}

Correspondence to: Dr Yoshimasa Maniwa, Division of Thoracic Surgery, Kobe University Graduate School of Medicine, 7-5-2 Kusuniki-cho, Chuo-ku, Kobe 650-0017, Japan

E-mail: maniwa@med.kobe-u.ac.jp

Key words: hRad9, non-small cell lung cancer, DNA damage, cell cycle checkpoint, Chk1 pathway, which appears to be essential for maintaining tumor cell proliferation, and induces cell death. Therefore, hRad9 may be a novel molecular target for lung cancer treatment.

\section{Introduction}

Human (h) hRad9, which has been mapped to the chromosome 11q13.1-13.2 (1), is a member of the family of DNA damage sensor proteins and forms a ring-like trimeric complex in conjunction with hRad1 and hHus1 (2-4). Molecular modeling analysis showed that the hRad9-hRad1-hHus1 (9-1-1) complex bears a structural similarity to the proliferating cell nuclear antigen (PCNA) that functions as a DNA sliding clamp for replicative DNA polymerases $(5,6)$. Moreover, 4 out of the 5 subunits of the 9-1-1 clamp loader Rad17-RFC are subunits of the PCNA clamp loader replication factor C (RFC) (6-8). These observations suggest that 9-1-1 functions as a checkpoint sliding clamp that encircles DNA and recruits the checkpoint signaling machinery to the sites of DNA lesions or stalled replication forks which induce cell cycle arrest $(9,10)$.

Several important properties are attributed to hRad9. Multiple phosphorylation sites have been detected near the carboxyl-terminus of the protein (11-13). In the absence of DNA damage, hRad9 is constitutively phosphorylated (14) and becomes hyperphosphorylated in response to DNA damage (15). Furthermore, the carboxyl-terminal region contains a nuclear localization sequence (NLS) that targets hRad9 into the nucleus (16). Reports showed that hRad9 is a key participant in the activation of Chk1-a protein kinase, which phosphorylates proteins that regulate the checkpoint response $(12,17)$, and that 9-1-1 interacted with DNA polymerase $B(18)$ and flap endonuclease 1 (19). These findings supported the direct participation of 9-1-1 in cell cycle arrest and DNA damage repair.

Although few studies on the role of hRad9 in tumor proliferation exist, we have confirmed that significant amounts of hyperphosphorylated hRad9 accumulate in the nuclei of tumor cells in surgically-resected non-small cell lung cancer (NSCLC) specimens (20) and that the capacity to produce a functional hRad9 protein is intact in lung cancer cells (21). These findings suggest that hRad 9 would be a vital component in the pathways that lead to the proliferation and 
progression of NSCLC. The current study is aimed at verifying the hypothesis that hRad9 acts as an oncogene in the cell cycle control of NSCLC.

\section{Materials and methods}

Cell lines. PC-3 (lung adenocarcinoma, moderately differentiated, http://www.jhsf.or.jp/bank/Category-Index.html) and A549 (bronchioloalveolar carcinoma of the lung) cell lines were obtained from the Health Science Research Resources Bank (Osaka, Japan). The WI-38 cell line was obtained from the Riken Bioresource Center (Tsukuba, Japan). The cells were maintained in RPMI-1640 medium supplemented with penicillin $(100 \mathrm{U} / \mathrm{ml})$, streptomycin $(100 \mathrm{U} / \mathrm{ml})$ and $10 \%$ bovine calf serum. The cells were incubated at $37^{\circ} \mathrm{C}$ in a humidified atmosphere of $95 \%$ air and $5 \% \mathrm{CO}_{2}$.

Small interfering RNA transfection. RNA interference was performed using hRAD9 siRNA (target sequence, AAG TCT TTC CTG TCT GTC TTC) and a non-silencing control siRNA (target sequence, AAT TCT CCG AAC GTG TCA CGT, Qiagen GmbH, Hilden, Germany) according to the manufacturer's instructions. Briefly, $24 \mu 1$ of transfection reagent (Hiperfect, Qiagen $\mathrm{GmbH}$ ) was suspended in $200 \mu \mathrm{l}$ of serum-free culture medium containing $20 \mu \mathrm{l}$ of $20 \mu \mathrm{M}$ siRNA solution. A549 or PC3 cells, seeded for $24 \mathrm{~h}$ at the bottom of a 24-well tissue culture plate at a density of 1500 cells/well, were treated with $400 \mu$ l culture medium (final concentration of siRNA, $225 \mathrm{nM}$ ) containing $50 \mu 1$ of the siRNA solution for $3 \mathrm{~h}$. The medium was then replaced with $400 \mu \mathrm{l}$ of the culture medium without the siRNA solution, and the cells were incubated in this medium. After $48 \mathrm{~h}$ of incubation, a second treatment was performed in the same manner, and the cells were incubated for a further $48 \mathrm{~h}$.

Western blot analysis. After removing the culture media and washing with phosphate-buffered saline (PBS), the cells at the bottom of the well were lysed with $500 \mu 1$ Laemmli sample buffer containing $100 \mathrm{mM}$ dithiothreitol. The extracts were centrifuged at $10,000 \times \mathrm{g}$ at $4^{\circ} \mathrm{C}$ for $5 \mathrm{~min}$ to remove debris. Ten microliters of the supernatant were heated in a boiling water bath for $4 \mathrm{~min}$ and subjected to sodium dodecyl sulfate (SDS)-polyacrylamide gel electrophoresis (PAGE) ( $10 \%$ polyacrylamide gel). The electrotransfer of proteins from the gel to a nitrocellulose membrane was carried out for $60 \mathrm{~min}$ at $240 \mathrm{~mA}$. The membrane was soaked in $5 \%$ defatted dry milk diluted with phosphate-buffered saline containing $0.02 \%$ Tween-20 (PBST) to reduce non-specific protein binding. The membrane was incubated for $45 \mathrm{~min}$ at room temperature with $50 \mu 1$ of anti-hRad9 (M-389) antibody (Santa Cruz Biotechnology, Santa Cruz, CA) diluted in $10 \mathrm{ml}$ of PBST containing 3\% bovine serum albumin (BSA) and then treated with a suitable secondary antibody (Amersham Biosciences, Tokyo, Japan) for $30 \mathrm{~min}$ at room temperature. Enhanced chemiluminescence was performed according to the manufacturer's instructions (Amersham Biosciences). Chemiluminescence was detected using an image analyzer (LAS-3000, Fujifilm, Tokyo, Japan). The same membrane was re-probed for the detection of $\beta$-actin, Chk1 and phosphorylated Chk1.
Immunofluorescence experiments. For immunofluorescence studies, the cells were seeded in culture slides (BD Falcon, Becton-Dickinson and Co., Franklin Lakes, NJ), followed by treatment with siRNA. The cells were washed twice in PBS, fixed in $2 \%$ paraformaldehyde for $15 \mathrm{~min}$ at $37^{\circ} \mathrm{C}$ and permeabilized with $0.2 \%$ Triton $\mathrm{X}-100 / \mathrm{PBS}$ for $15 \mathrm{~min}$ at $37^{\circ} \mathrm{C}$. After preblocking with $5 \% \mathrm{BSA} / \mathrm{PBS}$, the cells were incubated overnight at $4^{\circ} \mathrm{C}$ with hRad9 (M-389) antibody (Santa Cruz Biotechnology) diluted at 1:50 with 1\% BSA/ PBS. After washing with PBST and BSA/PBS, the cells were treated for $30 \mathrm{~min}$ at $37^{\circ} \mathrm{C}$ with fluorescein isothiocyanate (FITC)-conjugated secondary antibodies (Amersham Biosciences) diluted at 1:50 with $1 \% \mathrm{BSA} / \mathrm{PBS}$. The cells were washed in PBS and then stained with $0.4 \mu \mathrm{g} / \mathrm{ml}$ of the nuclear stain DAPI in antifade solution (Chemicon International, Temecula, CA).

Cytotoxicity assay. To evaluate the cytotoxicity of the hRad9RNAi treatment, a neutral red-uptake test was performed. Neutral red was added to each well at a final concentration of $50 \mathrm{mg} / \mathrm{ml}$, and the cultures were incubated for $1 \mathrm{~h}$. Each cell was fixed with $10 \%$ neutral formalin buffer, washed in water and air dried.

Fluorescence-activated cell-sorting analysis. Twenty-four hours after the second RNAi treatment, the A549 cells were irradiated with $20 \mathrm{~Gy}$. The irradiated cells were incubated for an additional $24 \mathrm{~h}$, fixed with $70 \%$ ethanol and then incubated for $30 \mathrm{~min}$ with $100 \mu \mathrm{g} / \mathrm{ml}$ RNase A and propidium iodide at room temperature. DNA content analysis was performed by flow cytometry.

\section{Results}

Confirmation of the wild-type hRad9 protein expression in cancer cells. The hRad9 gene sequence in A549 and PC-3 cells was analyzed to clarify whether the translated proteins were wild-type or mutant. All 11 exons were amplified by $\mathrm{PCR}$, and their sequences were completely analyzed by a previously reported method (21). No alteration was detected in their DNA.

Western blot analysis and immunofluorescence studies after hRad9 silencing. To evaluate the efficacy of hRad9-RNAi, Western blot analysis and immunofluorescence were performed. The treated cells were lysed and the protein extracts were subjected to SDS-PAGE. The nitrocellulose membrane with the transferred proteins was treated with the anti-hRad9 antibody, and the band for hRad9 was detected by chemiluminescence. hRad9 expression was decreased in silenced versus non-silenced cells (Fig. 1). Furthermore, the effect of the treatment was confirmed with immunofluorescence studies. The results indicated that the nuclear signals of fluorescein corresponding to hRad9 showed a marked decrease in the treated cells (Fig. 2).

Neutral red-uptake test. The neutral red-uptake test was performed to evaluate the cytotoxicity of transfected cancer cells. The cells showed significantly suppressed tumor cell growth after silencing compared with the control group 

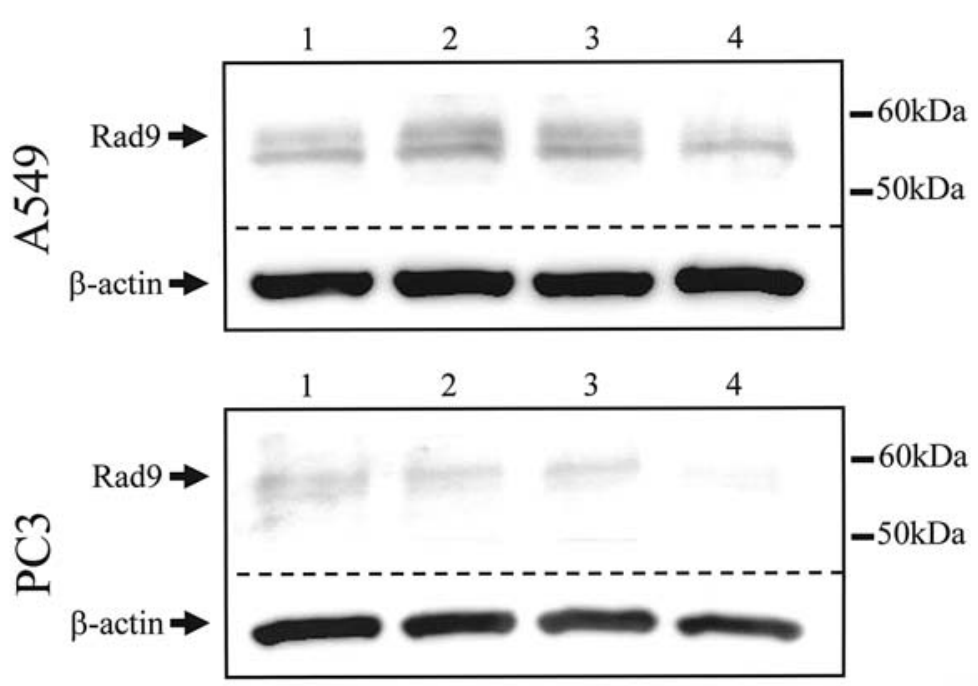

Figure 1. Western blot analysis after hRad9 silencing. To evaluate the efficacy of hRad9-RNAi, Western blotting was performed. Lane 1, samples from nontreated cells; lane 2, samples treated with a transfection reagent alone; lane 3, samples treated with non-silencing siRNA and lane 4, samples treated with hRad9-siRNA. RNAi treatment produced a marked decrease in hRad9 expression.

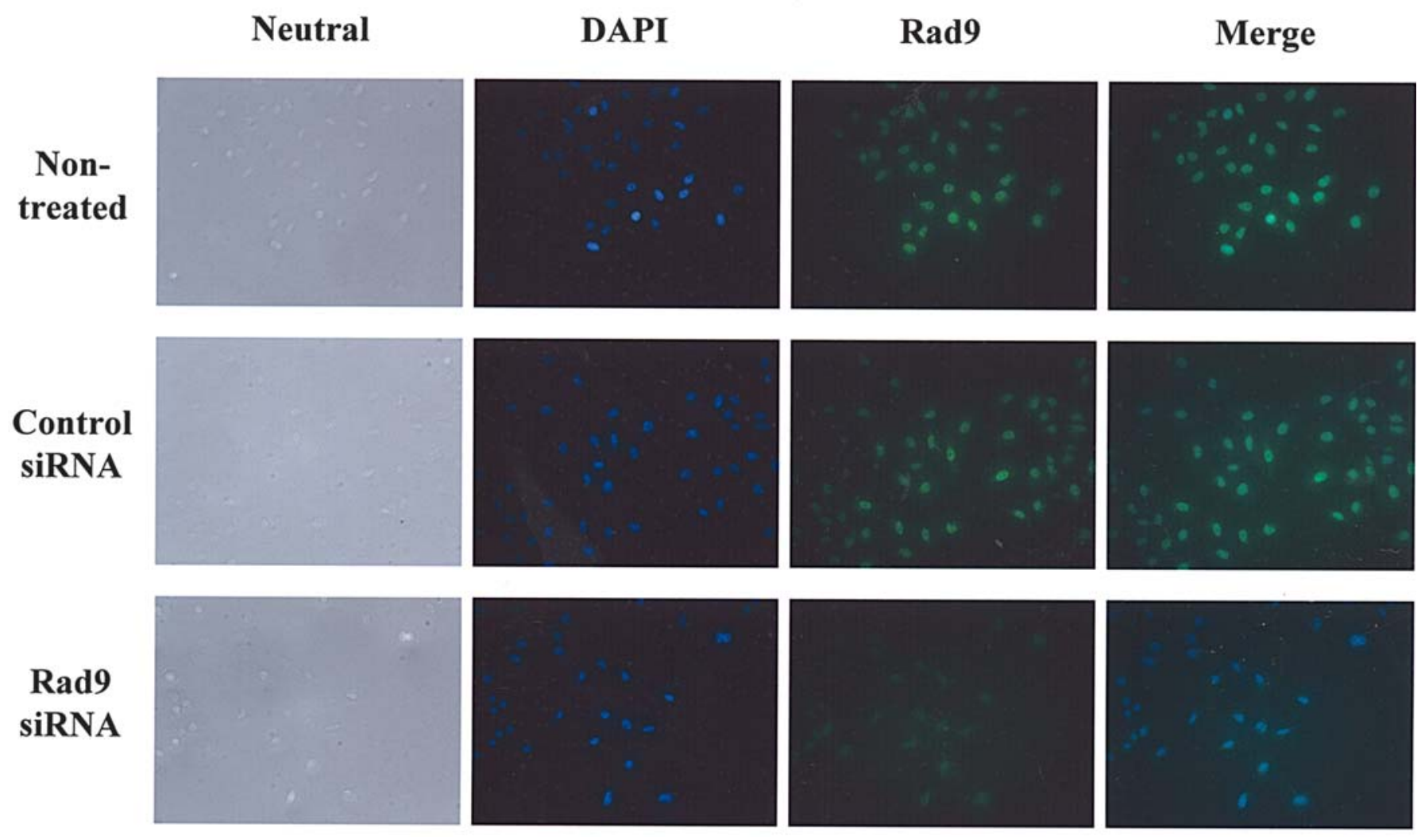

Figure 2. Immunofluorescence staining after hRad9 silencing. The immunofluorescence examination enabled visualization of the expression and nuclear localization of hRad9. Signals for hRad9 were green (FITC), and the nuclei were counterstained blue (DAPI). In hRad9-silenced cells (bottom panel), the merged signal appeared blue because of a weak FITC signal.

(Fig. 3). These results suggested that hRad9 fostered the survival and proliferation of cancer cells.

The knockdown of hRad9 promotes G2-M transition. It is well-known that hRad9 is hyperphosphorylated and strongly accumulated in the nuclei of irradiated cells (13-16). These findings suggested that hRad9 plays a role in the detection and repair of DNA strands injured by radiation. Therefore, we investigated the effect of irradiation on cancer cells in which hRad9 expression was transiently suppressed. After irradiation, the intranuclear DNA content of hRad9-silenced cells was measured by flow cytometry to analyze the proportion of cells at each phase of the cell cycle and compare these proportions with those observed for non-silencing cells. Until $12 \mathrm{~h}$ after irradiation, no difference between the two groups had been detected in the $\mathrm{G} 2$ phase population. 

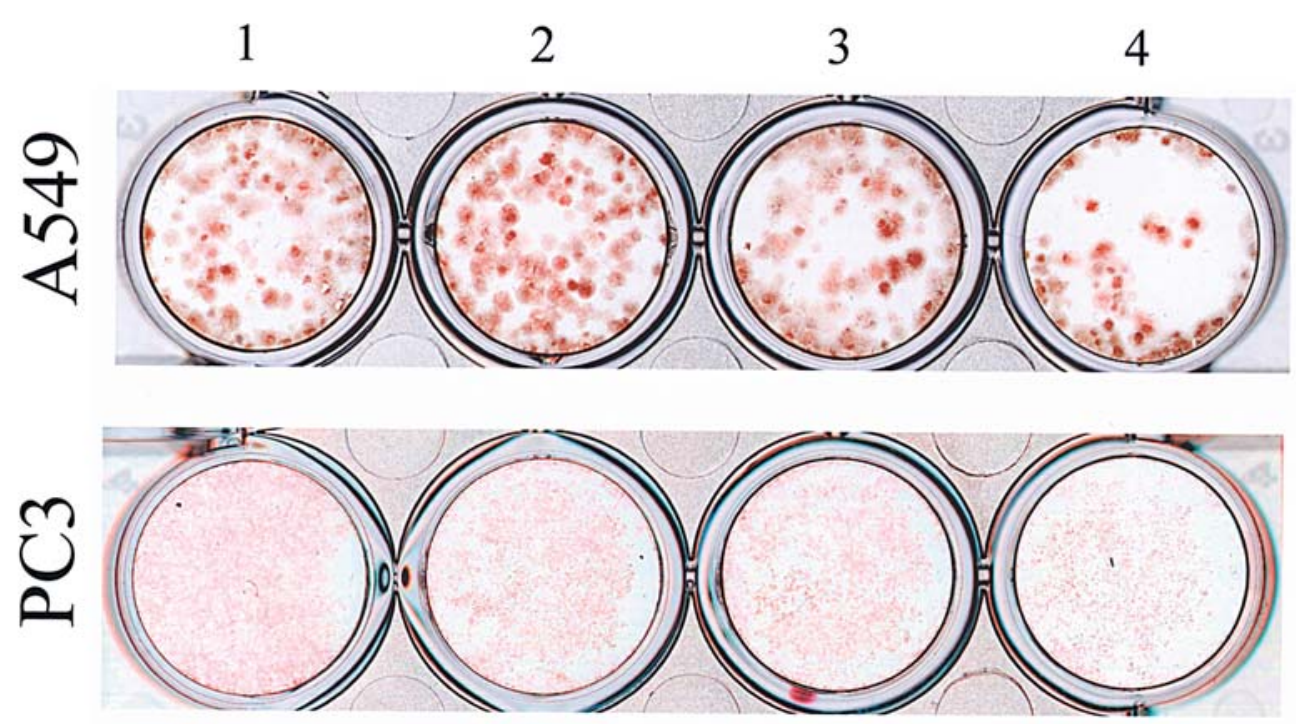

Figure 3. Visualization of the proliferation activity of lung cancer cells. A neutral red uptake test was performed to evaluate the cytotoxicity towards hRad9siRNA transfected cells. Cancer cells, seeded on a 24-well tissue culture plate, were treated twice with hRad9-siRNA over a 5-day incubation period. Lane 1, samples from non-treated cells; lane 2, samples treated with a transfection reagent alone; lane 3, samples treated with non-silencing siRNA and lane 4, samples treated with hRad9-siRNA. The number of living cells, which absorbed the red color, showed a marked decrease in the wells treated with hRad9-siRNA (Lane 4).

a

$0 \mathrm{hr}$
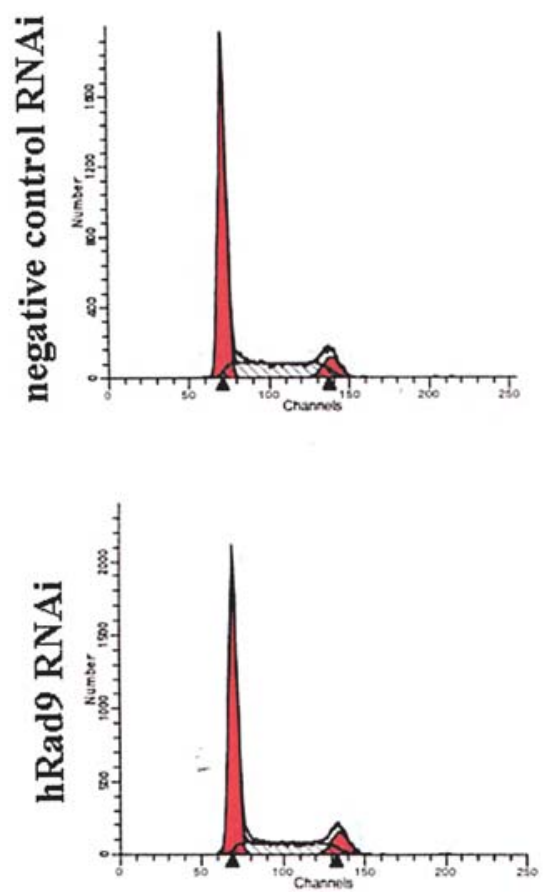

b

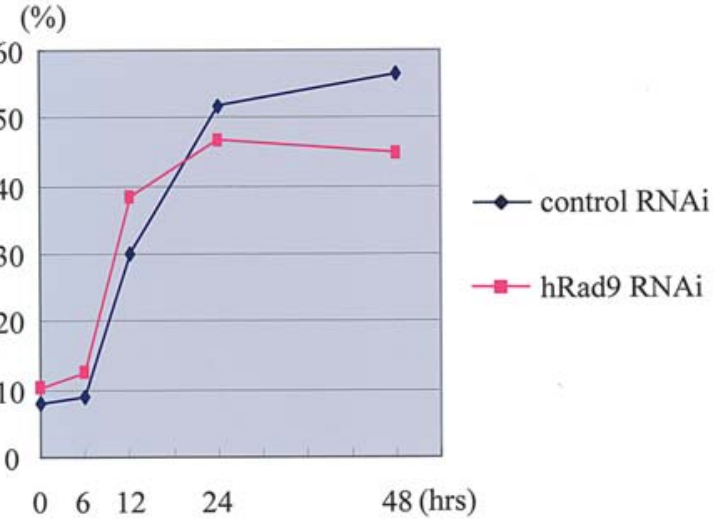

$24 \mathrm{hr}$
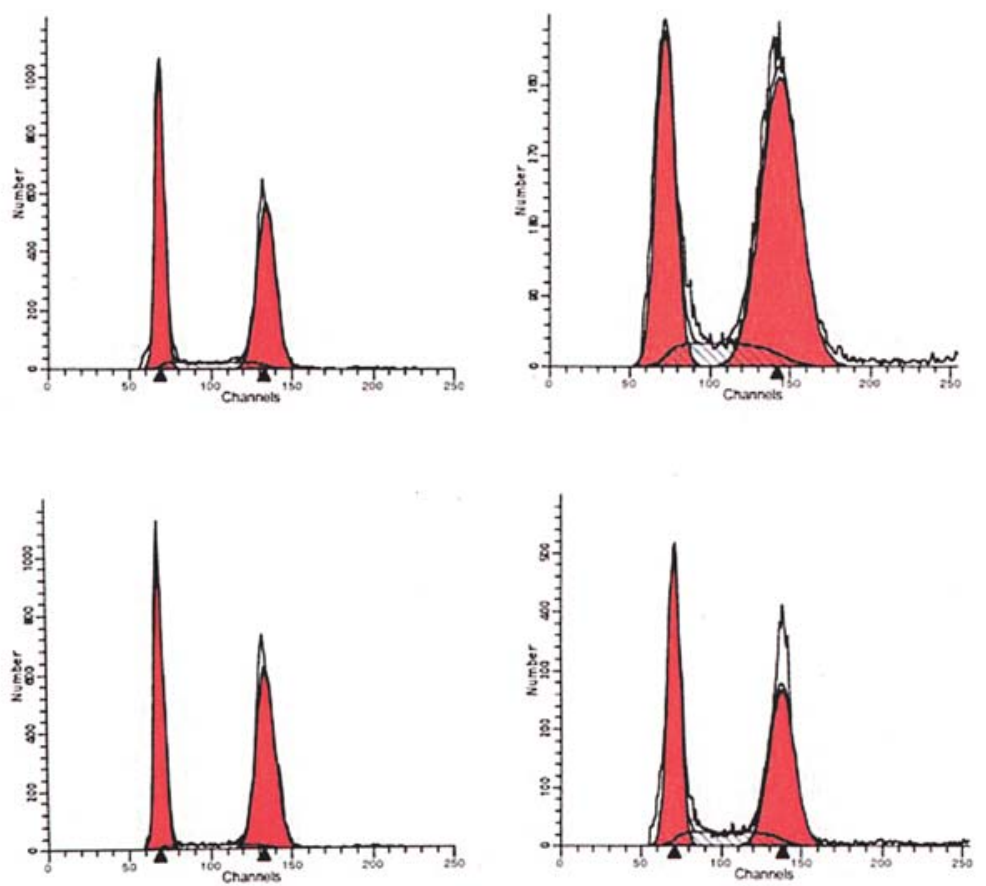

Figure 4. Disorder in G2-M arrest by knockdown of hRad9. To analyze the proportion of cells at each phase of the cell cycle, the intranuclear DNA content of hRad9-silenced cells was measured by flow cytometry. (a) The red areas show the distribution of the DNA content of the cells. The first peak indicates diploid cells, and the second the tetraploid condition. The enlargement of the second peak represents an increase in the proportion of cells in the G2 phase because of G2-M arrest. The number of tetraploid cells that were treated with hRad9-siRNA (bottom panel) markedly decreased $48 \mathrm{~h}$ after irradiation compared with the number of non-silenced cells (top panel). (b) Percentage of tetraploid cells. Until $12 \mathrm{~h}$ after irradiation, no difference between the two groups was detected with regard to the proportion of cells in the G2 phase. However, an apparent decrease in the proportion of cells arrested at the G2-M checkpoint was observed in the hRad9-silenced group at $48 \mathrm{~h}$ after irradiation. This suggested that hRad9 had an important role in sustaining the G2-M arrest for a longer period. 


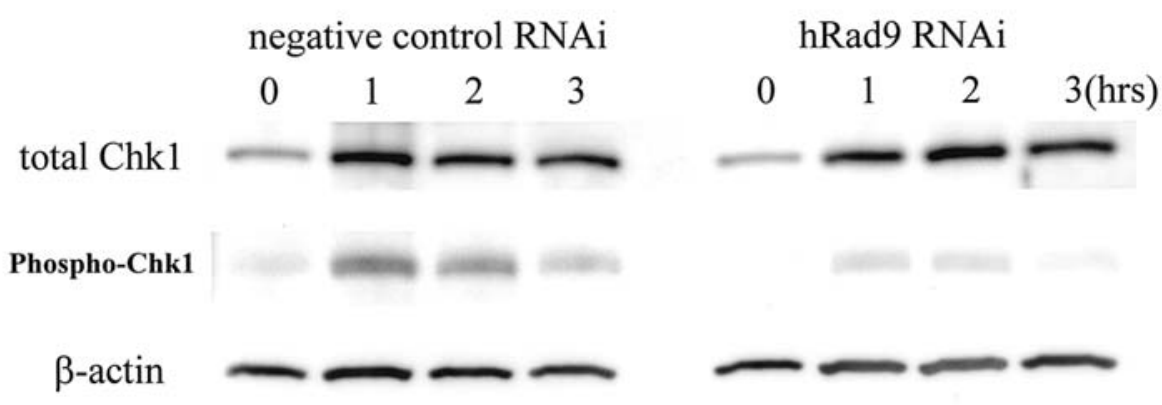

Figure 5. The expression and phosphorylation state of Chk1 after irradiation in hRad9-silenced cells. Western blot analysis of the cell lysates of hRad9silenced and non-silenced cells after irradiation was performed. The total Chk1 was increased in the two groups after irradiation (top panel). In the non-silenced cells, phosphorylated Chk1 was strongly detected $1 \mathrm{~h}$ after irradiation and it faded out gradually. However, it was weakly detected in the hRad9-silenced cells (middle panel).

However, an apparent decrease in the population of cells arrested at the G2-M checkpoint was observed in the hRad9silenced group (Fig. 4). This suggested that hRad9 plays an important role in sustaining the G2-M arrest longer.

Chk1 is a protein kinase which phosphorylates proteins that regulate the checkpoint response $(22,23)$, and hRad9 is a key participant in the Chk1 activation pathway $(12,18)$. We examined the expression and phosphorylation state of Chk1 to evaluate whether the hRad9 protein in irradiated cancer cells was related to the DNA damage checkpoint signaling pathway in these cancer cells. Western blot analysis of the cell lysates showed an increased phosphorylation of Chk1 after irradiation of the non-silenced cells. The phosphorylation of Chk1 was markedly weaker in hRad9-silenced versus nonsilenced cells (Fig. 5). This correlation suggests that the hRad9-Chk1 pathway functions in the cells, and hRad9 silencing deteriorated Chk1 hyperphosphorylation and cell arrest in irradiated cells.

\section{Discussion}

We previously reported that the hRad9 protein, which accumulated in the nuclei of NSCLC cells, was heavily phosphorylated, as was Chk1, a key protein kinase involved in the DNA damage checkpoint pathway (20). We also demonstrated that there were no sequence alterations in $H R A D 9$ in lung carcinoma cells and that HRAD9 was transcribed normally in these cells (21). These findings led to the hypothesis that hRad9 functions as an oncogene in cancer cells. Genomic instability is commonly observed in cancer cells, and it is considered to be a cause of genetic alterations and carcinogenesis. Life-threatening alterations in DNA also occur in cancer cells, placing the cells in a critical state. In such conditions, cancer cells would require a DNA-damage repair mechanism to maintain stability. Functional hRad9 may help cancer cells to avoid death and maintain immortal proliferation.

Although there is considerable information concerning the function of hRad9, its role in cancer cells has yet to be explored. The overexpression of HRAD 9 mRNA is frequently detected in breast cancer and this change has implications in tumor proliferation and local invasion (24). These clinical observations suggest that hRad9 is a new candidate oncogene.
In the present study, we successfully repressed hRad9 expression in NSCLC using RNA interference, which was confirmed by Western blot analysis and immunohistochemistry. As was expected, a neutral red uptake test demonstrated that the hRad9 repression reduced the proliferation of lung cancer cells, which indicated that hRad9 plays a role in the proliferation of cancer cells.

It is well-known that hRad9 is activated in irradiated cells (11-16). We investigated the role of hRad9 in irradiated lung cancer cells. A fluorescence-activated cell-sorting analysis of irradiated cells showed the influence of hRad9 knockdown in the G2-M arrest. During the early phase (6 and $12 \mathrm{~h}$ after irradiation), no difference between the hRad9-silenced and control groups was observed in the proportion of G2 cells. However, $24 \mathrm{~h}$ later, the G2 proportion started shrinking in the silenced group, but was sustained for $48 \mathrm{~h}$ in the non-silenced group. This implies that hRad9 mainly contributes to the maintenance of the G2-M arrest to repair DNA damage rather than to the initiation of the G2-M arrest, a finding consistent with that of a previous study (25). Complete DNA damage repair requires time which hRad9 appears to increase. These findings markedly indicate that hRad9 not only triggers cell cycle arrest but also contributes to the repair of damaged DNA.

If damaged cells enter the mitotic phase without complete DNA repair, cell disintegration occurs. This is called mitotic catastrophe (26). An insufficiency in DNA damage repair proteins appears to trigger this type of cell death. In contrast, the DNA of a cancer cell is easily injured because of its genomic instability. Should such cells enter mitosis without passing through the G2-M checkpoint, they undergo mitotic catastrophe. In hRad9-silenced cells, mitotic catastrophe induced by checkpoint insufficiency appeared to reduce their proliferation ability. Irradiation and a few anticancer drugs attack the DNA of cancer cells and induce mitotic catastrophe. The antitumor activity of these agents must be enhanced in combination with the hRad9 knockdown.

Western blot analysis showed a reduction in the amount of phosphorylated Chk1 consistent with hRad9 regression, suggesting that hRad9 silencing deteriorated Chk1 hyperphosphorylation in cancer cells. It was reported that 9-1-1 activation facilitates Chk1 hyperphosphorylation in Ataxia telangiectasia-Rad3 (ATR)-dependent cell cycle signaling (17), 
and this cooperation also appears to be maintained in lung cancer cells. Consequently, the intracellular pathway involving these proteins must be a good candidate for moleculartargeting cancer therapy.

In conclusion, the expression of hRad9 in lung cancer cells was suppressed using the RNAi procedure to clarify whether hRad9 is a good candidate for molecular cancer therapy. The proliferative ability of hRad9-silenced cells significantly decreased. In combination with radiation, hRad9 appears to induce mitotic catastrophe in cancer cells because of the insufficient duration of the G2-M arrest. hRad9 functions in lung cancer cells as an oncogene and appears to be a molecular target for lung cancer treatment.

\section{References}

1. Lieberman HB, Hopkins KM, Nass M, Demetrick D and Davey S: A human homolog of the Schizosaccharomyces pombe hRad $^{+}$checkpoint control gene. Proc Natl Acad Sci USA 93: 13890-13895, 1996.

2. Burtelow MA, Roos-Mattjus PM, Rauen M, Babendure JR and Karnitz LM: Reconstitution and molecular analysis of the hRad9-hHus1-hRad1 (9-1-1) DNA damage responsive checkpoint complex. J Biol Chem 276: 25903-25909, 2001.

3. Shiomi Y, Shinozaki A, Nakada D, Sugimoto K, Usukura J, Obuse $\mathrm{C}$ and Tsurimoto T: Clamp and clamp loader structures of the human checkpoint protein complexes, Rad9-1-1 and Rad17-RFC. Genes Cells 7: 861-868, 2002.

4. Volkmer E and Karnitz LM: Human homologs of Schizosaccharomyces pombe rad1, hus 1 and hRad9 form a DNA damage-responsive protein complex. J Biol Chem 274: 567-570, 1999.

5. Venclovas $\mathrm{C}$ and Thelen MP: Structure-based predictions of Rad1, Rad9, Hus1 and Rad17 participation in sliding clamp and clamp-loading complexes. Nucleic Acids Res 28: 2481-2493, 2000.

6. Green CM, Erdjument-Bromage H, Tempst P and Lowndes NF: A novel Rad24 checkpoint protein complex closely related to replication factor C. Curr Biol 10: 39-42, 2000.

7. Lindsey-Boltz LA, Bermudez VP, Hurwitz J and Sancar A: Purification and characterization of human DNA damage checkpoint Rad complexes. Proc Natl Acad Sci USA 98: 11236-11241, 2001.

8. Kondo T, Matsumoto K and Sugimoto K: Role of a complex containing Rad17, Mec3 and Ddc1 in the yeast DNA damage checkpoint pathway. Mol Cell Biol 19: 1136-1143, 1999.

9. Bermudez VP, Lindsey-Boltz LA, Cesare AJ, Maniwa Y, Griffith JD, Hurwitz J and Sancar A: Loading of the human 9-1-1 checkpoint complex onto DNA by the checkpoint clamp loader hRad17-replication factor C complex in vitro. Proc Natl Acad Sci USA 100: 1633-1638, 2003.

10. Rauen M, Burtelow MA, Dufault VM and Karnitz LM: The human checkpoint protein hRad17 interacts with the PCNAlike proteins hRad1, hHus1 and hRad9. J Biol Chem 275: 29767-29771, 2000.

11. St Onge RP, Besley BD, Park M, Casselman R and Davey S: DNA damage-dependent and -independent phosphorylation of the hRad9 checkpoint protein. J Biol Chem 276: 41898-41905, 2001.
12. Roos-Mattjus PM, Hopkins KM, Oestreich AJ, Vroman BT, Johnson KL, Naylor S, Lieberman HB and Karnitz LM: Phosphorylation of human Rad9 is required for genotoxinactivated checkpoint signaling. J Biol Chem 278: 24428-24437, 2003.

13. St Onge RP, Besley BD, Pelley JL and Davey S: A role for the phosphorylation of hRad9 in checkpoint signaling. J Biol Chem 278: 26620-26628, 2003.

14. St. Onge RP, Udell CM, Casselman R and Davey S: The human G2 checkpoint control protein hRad9 is a nuclear phosphoprotein that forms complexes with hRAD1 and hHUS1. Mol Biol Cell 10: 1985-1995, 1999

15. Chen MJ, Lin YT, Lieberman HB, Chen G and Lee EY: ATMdependent phosphorylation of human HRad9 is required for ionizing radiation-induced checkpoint activation. J Biol Chem 276: 16580-16586, 2001.

16. Hirai I and Wang HG: A role of the C-terminal region of human Rad9 (hRad9) in nuclear transport of the hRad9 checkpoint complex. J Biol Chem 277: 25722-25727, 2002.

17. Furuya K, Poitelea M, Guo L, Caspari T and Carr AM: Chk1 activation requires hRad9 S/TQ-site phosphorylation to promote association with C-terminal BRCT domains of Rad4TOPBP1. Genes Dev 18: 1154-1164, 2004.

18. Toueille M, El-Andaloussi N, Frouin I, Freire R, Funk D, Shevelev I, Friedrich-Heineken E, Villani G, Hottiger MO and Hübscher U: The human Rad9/Rad1/Hus1 damage sensor clamp interacts with DNA polymerase beta and increases its DNA substrate utilisation efficiency: implications for DNA repair. Nucleic Acids Res 32: 3316-3324, 2004.

19. Wang W, Brandt P, Rossi ML, Lindsey-Boltz L, Podust V, Fanning E, Sancar A and Bambara RA: The human Rad9-Rad1Hus1 checkpoint complex stimulates flap endonuclease 1. Proc Natl Acad Sci USA 101: 16762-16767, 2004.

20. Maniwa Y, Yoshimura M, Bermudez VP, Yuki T, Okada K, Kanomata N, Ohbayashi C, Hayashi Y, Hurwitz J and Okita Y: Accumulation of hRad9 protein in the nuclei of non-small cell lung carcinoma cells. Cancer 103: 126-132, 2005.

21. Maniwa Y, Yoshimura M, Bermudez VP, Okada K, Kanomata N, Ohbayashi C, Nishimura Y, Hayashi Y, Hurwitz J and Okita Y: His239Arg SNP of HRAD9 is associated with lung adenocarcinoma. Cancer 106: 1117-1122, 2006.

22. Rhind N and Russell P: Chk1 and Cds1: linchpins of the DNA damage and replication checkpoint pathways. J Cell Sci 113: 3889-3896, 2000.

23. Bartek $\mathbf{J}$ and Lukas $\mathrm{J}$ : Chk1 and Chk2 kinases in checkpoint control and cancer. Cancer Cell 3: 421-429, 2003.

24. Cheng CK, Chow LW, Loo WT, Chan TK and Chan V: The cell cycle checkpoint gene hRad9 is a novel oncogene activated by $11 \mathrm{q} 13$ amplification and DNA methylation in breast cancer. Cancer Res 65: 8646-8654, 2005.

25. Brandt PD, Helt CE, Keng PC and Bambara RA: The hRad9 protein enhances survival and promotes DNA repair following exposure to ionizing radiation. Biochem Biophys Res Commun 347: 232-237, 2006 .

26. Castedo M, Perfettini JL, Roumier T, Andreau K, Medema R and Kroemer G: Cell death by mitotic catastrophe: a molecular definition. Oncogene 23: 2825-2837, 2004. 